\title{
RESEARCH DEVELOPMENT, CHALLENGES AND OPPORTUNITIES AT THE DEPARTMENT OF CIVIL ENGINEERING AT PRINCE MOHAMMAD BIN FAHD UNIVERSITY
}

\author{
Tahar Ayadat a, Omar Ouda b, Alaa Salman c, Danish Ahmed d, Andi Asiz e \\ abcde Prince Mohammad bin Fahd University, Al Khobar, Saudi Arabia \\ Corresponding email: aasiz@pmu.edu.sa
}

\begin{abstract}
The main objectives of this paper are to present advanced research development and activities at the Department of Civil Engineering at Prince Mohammad Bin Fahd University (PMU) and to discuss expected research outcomes and its contributions to Saudi's society. Currently the department is supported by five teaching staffs comprises of four full time professors with PhDs and one laboratory instructor at master degree's level. The research areas within the department are very diverse incorporating main civil engineering faculty expertise in the fields of environmental, geotechnical, construction and structural engineering with minor research activities in the area of engineering education. The research infrastructures such as advanced computer simulation and state-the-art engineering laboratories are being established in the department and graduate program which will offer initially master degree under civil engineering is being developed. Research strategies, challenges and opportunities at the department -- with the university being focused on teaching activities while building foundations for research infrastructures-- will be discussed. Discussion followed by recommendations will be given to improve research performance at the department.
\end{abstract}

Keywords: Research Development, Challenges, Opportunities; Civil Engineering; PMU.

\section{Introduction}

Research and Development is one of the key missions of the modern university with common intention to provoke creative thinking and to promote innovations that benefit society. At Prince Mohammad Bin Fahd University (PMU), the culture of research is institutionalized in a mission that guide research activities to create solutions for persistent problems in surrounding communities through applied research and technical consultation. Despite of emphasizing on applied research, the importance of performing basic research for enriching human intelligence is encouraged to be in-line with the other PMU mission in promulgation and development of knowledge. At PMU, unlike other universities in the developed nations, research is facilitated via Deanship of Research Development which at the moment is focusing its activity assisting faculty securing internal research funding to initiate and expand research ideas. PMU is a relatively young private university established in 2006 in the Eastern Province of Saudi Arabia. It has currently close to 4000 students and more than 250 teaching staff across male and female campuses with four major colleges: COE (College of Engineering), COBA (College of Business Administration), CCES (College of Computer Engineering and Sciences), and CSHS (College Science and Human Study). COE is amongst the leader in the research activities at PMU due to more than 80 percent of the faculty being PhD holders particularly those who are in the male campus units (Electrical, Civil, and Mechanical Engineering Departments). 
The Department of Civil Engineering at PMU has adhered to the university research mission through one of its program objectives - to explore, enhance and expand the knowledge in the civil engineering areas by conducting innovative research and scholarly activity. The department has total number of 180 students with five teaching staff, implying that based on studentfaculty-ratio teaching will take a big proportion of faculty time. Research infrastructure including modern state-of-the art computers and engineering laboratories are being commissioned and it is anticipated that in the early 2017 all laboratories will be ready to operate with first major activities focused on teaching and gradually shared toward research. A graduate program at Masters level is being proposed and surveys have been conducted to ascertain which strong fields within the civil engineering program are highly needed in the construction industry.

It can be deduced from the above situation that the department seems to be oriented toward teaching rather than being research-based considering the non-existence of graduate programs and ongoing establishment of research laboratories. However, supported by previous professional and academic experiences of the faculty, research activities are vibrant and intense within the department utilizing strategies that are adaptable to limited research resources. These strategies include but not limited to: collaborative work with other national and international institutions, data collection and analysis, extensive numerical or computer modeling and analysis, and research in engineering education.

Active research areas in the department include environmental, geotechnical, construction, structural engineering, and engineering education. The following is description of the research focuses, strategies, activities, challenges, opportunities, and expected outcomes or impacts for each discipline.

\section{Environmental Engineering}

The environmental management in the Kingdom of Saudi Arabia is suboptimal in comparison to the state of economy of the country. The Kingdom is challenged with many environmental issues that need special attention and analysis (Ouda, 2013 a; 2013 b; Ouda, et al, 2013a; 2013b). Since the establishment of the Department of Civil Engineering at PMU, extensive works have been conducted to optimize the performance of environmental sector in the Kingdom and worldwide based on strong collaboration with scholars from national and international universities and research institutes. The environmental research group focuses their research on the most stressing environmental issues in the Kingdom: Water Resources Management and Solid Waste Management. With respect to these research themes, collaboration with external institutions led by environmental engineering faculty at PMU has been established involving large public universities (e.g. KFUPM, KAA, and KSU), industry and government regulators in KSA. The following is brief descriptions about these two research themes, activities, and impacts.

\section{Water Resources Management}

For the last 40 years, water scarcity in the Middle East has been a well-known and alarming problem. The Middle East as a region ran out of water in the 1970 s and the region lost its ability to achieve food self-sufficiency from renewable water resources. Currently, national governments and research institutions are increasingly concerned about water scarcity that is threatening the economic development and political stability of many parts of the region. The KSA has very limited water resources with an average yearly rainfall of about $100 \mathrm{~mm}$. The percapita water share from natural water resources was about $188 \mathrm{~m}^{3}$ per year in 2010 , whilst the 
per-capita average water consumption was about $650 \mathrm{~m}^{3}$ per year. The per-capita water share in the KSA is far below the UNESCO water scarcity index of $1000 \mathrm{~m}^{3}$. Accordingly, the country is under extreme water scarcity conditions. The sustainable water resource yield was estimated at about 6.44 billion $\mathrm{m}^{3}$ in 2010 whilst the total water demand was about 17.86 billion $\mathrm{m}^{3}$, as listed Table 1. The gap between sustainable water resource yields versus total demand was about 11.5 billion $\mathrm{m}^{3}$ in 2010. The water demand versus supply gap is historically bridged through groundwater depletion, and sea-water desalination (Ouda, 2014)

Table 1: KSA Sustainable Water Resources Yields

\begin{tabular}{lll}
\hline Water Sources & $\begin{array}{l}\text { Quantity } \\
\text { (million } \\
\text { m3/year) } \\
\end{array}$ & \\
& 2010 & 2014 \\
\hline Groundwater & 3,850 a & 3,850 \\
Surface water & $1,300^{*}$ & $2,400^{*}$ \\
Total conventional Sources & 5,150 & 6,250 \\
Treated wastewater & 240 & 400 \\
Desalinated water & 1,050 & 2,070 \\
Total non-conventional sources & 1,290 & 2,470 \\
Total & 6,440 & 8,720 \\
\hline *Variable depending on rainfall pattern & &
\end{tabular}

*Variable depending on rainfall pattern

The civil engineering department scholars have heavily investigated the various technical, economic, social and environmental aspects and impacts of the Kingdom challenging water problems. The Department Scholar outputs of more than 20 scientific papers have provided an in-depth analysis of the water management status in the Kingdom and have been published in a very high ranked ISI journals and conferences. The publications were very well appreciated and received from other scholars and water sector officials in the country and worldwide (Ouda et al, 2014 a; Ouda, 2015; Ouda, 2016).

\section{Solid Waste Management}

Municipal solid waste (MSW) should be considered as a valuable source for recycled materials and energy ( Ouda 2013c; Sadef, et al, 2016; Nizami, et al, 2016 a). The benefits from MSW are immense and are unquestionable for countries like KSA and the other Gulf countries as they may help in saving the primary source of energy in this part of the world. Currently, municipalities are governing MSW management in the KSA. The extent of MSW provision in the KSA is simple: collect and get rid of it by dumping it in open landfill sites. In addition, the low cost of landfills makes a large MSW recycling program implementation unachievable for the time being. The only large scale recycling system that currently exists is the trash sorters labor collection of metals and cardboards from garbage containers. The KSA currently generates about 16 million tons of MSW per year with an average of $1.4 \mathrm{~kg} /$ capita/day. The landfill requirement is about 2.8 million square meters per year. The MSW wastes of the KSA include $37 \%$ organic materials, $28.5 \%$ paper, $5.2 \%$ plastics, $8.3 \%$ mineral, $4.6 \%$ glass, $8 \%$ wood, $6.4 \%$ textile, and $2 \%$ others. The above average MSW production rate is the result of the lack of community-wide programs to enhance environmental awareness, and to encourage reduction of 


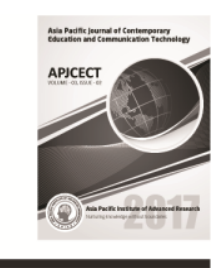

MSW generation, and to promote recycling. The on-going MSW disposal practices in the Kingdom heavily impact the environment thought soil, water, and air contaminations of the dump sites areas and vicinities (Ouda et al, 2013; Rehan et al, 2016; Nizami et al, 2016b).

US EPA considered Waste to Energy (WTE) technology as a renewable source of electricity with less environmental impacts than almost any other sources. WTE reduces the amount of MSW deposited at landfill sites; typically about 90\% volume reduction and $80 \%$ mass reduction. Incineration also minimizes leachate and methane formation and odor emissions. Methane is 21 times more detrimental than carbon dioxide from the global warming perspective. Many of landfills in KSA are mature landfills in that substantial amount of volume has already been used by municipal waste deposits. With additional dumping, the amount of undesirable by-products such as leachate, municipal waste sludge, renegade methane and odor emissions and all health hazards associated with these will keep increasing. The KSA does not have any WTE facility in place. The huge annual quantity of MSW and its high energy contents show the significant potential for WTE facilities in the Kingdom and its value to alleviate the significant environmental impacts of the on-going waste disposal practices.

The department scholars have heavily investigated the value of WTE to the Kingdom as a renewable energy source and MSW disposal technology. Their works have resulted in more than 30 scientific papers published in very high ranked ISI journals and conferences (Nizami et al, 2015a; 2015b; Ouda et al, 2016 a). The publications were well appreciated and received from other scholars and sector officials in the country and worldwide and as a result plan is in place right now to develop the first WTE Facility in the Eastern Province of Saudi Arabia.

\section{Geotechnical Engineering}

The research interests in geotechnical engineering cover an array of topics, including behavior of difficult soils; foundations design on difficult soils; performance of stone column foundations, pile foundations and soil anchors; slope stability problems; instrumentations, methods and procedures for laboratory and field soil testing (Ayadat, 2017a \& 2017b; Ayadat, 2016a \& 2016b; Hanna et al., 2016; Etezad et al. 2016; Hanna et al., 2015). The ongoing research projects focus on the distribution, classification, and the determination of the physical and mechanical properties of difficult soils in the eastern province of KSA. The surface geology of eastern Saudi Arabia is composed of consolidated and unconsolidated sediments. The consolidated sediments are of Palcocene to middle Eocene and Miocene to Piocene age, while the unconsolidated materials include Quaternary sabkha deposits, gravels, sands, and clays (AlHarbi, et al., 2015). Research is to be conducted using our extensive geotechnical engineering laboratory, and existing local in situ and laboratory data. In general the research is organized and managed within several research topics and groups.

One of these topics is conducted with broad objectives of reporting geological and geotechnical zonation maps for potentially collapsible and liquefiable soils in inhabited areas of Al-Khobar (Ayadat, et al., 2016). The main objectives of this study are reporting geological and geotechnical zonation maps for potentially collapsible and liquefiable soils in the area of Al-Khobar; implementing soil profiles, ground-water conditions and soil properties (i.e. physical and mechanical properties) for the different zones of the area, and suggesting some guidelines concerning foundation design on such soils. The impact the research will have and the applied benefits of the proposed project to the Eastern Region industry, economy, and society of KSA can be identified as follow: the zonation maps will reduce the cost of geotechnical investigations 


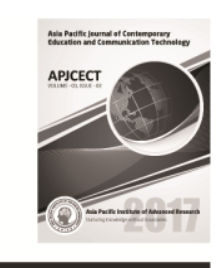

and hence the cost of construction projects in the area, notably medium sized projects. Therefore, economically impacts on the construction projects' expenses. The maps serve for rapid location of collapsible and liquefiable soils for any projected construction, and hence saving tremendously the timing of any preliminary investigation and the overall timing of any project. The development of these predicting maps will help selecting the appropriate and safe foundation systems, and hence reduces or eliminates mitigation.

A recent research topic in the department deals with the identification and determination of the physical and mechanical properties of Sabkha soils encountered in the area of Al-Khobar. Correlations between the different properties will be also investigated. Furthermore, some treatment or ground improvement methods of these soils (i.e. the sabkha soils of the region) will be assessed in the laboratory. The main goal of this assessment is to determine the more appropriate treatment methods for improving the characteristics of Sabkha soils, notably bearing capacity and settlement reduction.

It is anticipated that collaboration with local construction industry will be developed considering critical data collection needed to conduct the research. Also, geotechnical engineering laboratory which just has been established will be fully utilized to process some of the soil samples. International collaboration that has already been run between PMU and Concordia University in Montreal-Canada will be continued and updated.

\section{Construction Engineering and Management}

Current research in the field of construction engineering and management can be divided into two approaches: the first approach is research on Infrastructure Asset Management, and the second approach is research on the concept of construction management. Infrastructure Asset Management is considered a new field of research (IPWEA and NAMS, 2015). The conducted research aims toward achieving one of the most important goals of Saudi Vision 2030, issuing Saudi Infrastructure Report Card (IRC).

With recent developments in managing municipal's infrastructure assets, more efforts are required in KSA in this field. The first step toward this development is issuing a city report card. A typical report card includes a list of infrastructure assets such as energy, road, water, wastewater, bridges, public facilities(ASCE, 2013). Each asset is given a grade based on its physical condition. Most cities in developed countries have report cards, which are updated after one to four years. Generally, several factors affect the physical condition of an asset such as age, deterioration degree, location, material, external and internal loads, etc. (IPWEA and NAMS, 2012). The benefits of getting a physical condition assessment (CA) of an asset are (1) calculating the required maintenance expenses, (2) estimating the remaining service of life, (3) identifying the probability of failure, and (4) deciding what the required action must be done to keep the provided service without shortage. Issuing a report card helps leaders, decision makers, and municipal engineers to estimate required budget. In addition, Business Management Plan (BMP) can be done accordingly, based on the status of report card, to depict budget allocation and optimum expenses for short (Tactical) and long terms (Strategic) for all infrastructure assets. Hence, getting report cards for Saudi's cities help leaders, decision makers, and engineers to develop a Business Management Plan (BMP) "based on the actual needs and available budget”. 


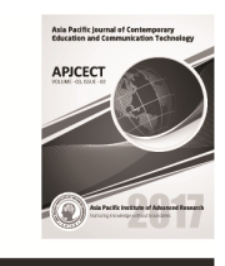

The second approach is research on the concept of construction management such as optimization of project scheduling, cost estimation, and cost control. Dealing with several variables of a project, it is necessary to consider the project as an integration of many processes to achieve project goals such as controlling cost, time, and quality (PMI, 2011). For instance, optimum scheduling can be achieved with respect to an ideal resource allocation and available cash flow. The expected output will be three dimensional model representing an optimum schedule. Project managers can use this model in their projects to efficiently monitor, control, and decide required actions to achieve project objectives.

Collaborations have been developed involving researchers from Dammam University and King Fahd University of Petroleum and Minerals, two established universities surrounding PMU. Also, key partnership with local municipality (e.g. Al Khobar Municipality) has been initiated to gain access to infrastructure data and management practices. It should be noted that the faculty with the expertise in this area joined the department in 2015; therefore, research has just been initiated.

\section{Structural Engineering}

Current research activity is focused on the development of numerical modeling and analysis of structural building components and systems utilizing innovative and green construction materials. The key research strategies here are obtaining verified data for computer modeling input and availability of reliable computer software to execute parametric study, i.e. finding optimum design solution. To overcome these challenges, all pertinent data for computer models are taken and derived from data obtained by collaborative research partners who are performing experimental work through their advanced laboratory facility. Modern computer software capable of performing state-the art of structural design solution is highly needed to conduct this type of research, and the respected faculties have acquired software funded by PMU through internal research grant. Since at the moment there are no graduate students, at some occasion senior graduating students at PMU were involved in executing some of the research exercises as part of their graduation project.

Recent research topic in this area is investigating alternative design for tall buildings with a ultra-lightweight floor system (A. Asiz et al., 2013; M. Ajmal et al., 2016). Main research collaborators in this subject are from the University of New Brunswick (UNB) and FPInnovation - Forintek Division, both are from Canada. Research finding has indicated that it is feasible to design tall building (up to 6o stories) using an ultra-lightweight floor. So far nine journal papers and conferences have been produced in this subject involving researchers mainly from PMU and UNB in Canada. The research outcomes in general will give architects and structural engineers who work in building design a new perspective of utilizing high performance materials that are not only sound and safe but also cost competitive and supporting of the environment (sustainable). By utilizing ultra-lightweight floor, the building demand on foundation will be reduced and this will lead to lower demand on land use. This is particularly true if the building is to be constructed in a very tightly packed city populated with buildings and infrastructure facilities. The outcome is applicable not only in Saudi Arabia, but also around the world where tall building constructions are in high demand. Therefore, the research outcomes are anticipated to be general and can be used in everywhere giving potential for further international research collaboration. 
Future research activities in the structural engineering area will be geared toward expanding numerical modelling and analysis capability using actual case studies and development of experimental work using established Material Engineering Laboratory. Green building and sustainable infrastructure engineering are also research areas that would be investigated due to the fact large energy consumption for running building and operating infrastructures.

\section{Engineering Education}

Engineering education is a common trend for research in a teaching oriented university, although some research based universities have conducted this type of study as part of faculty research interests in addition to their major research expertise. At PMU civil engineering department, research in engineering education aims at improving learning outcome achievement for students, harnessing teaching skills of faculty, and upgrading the curriculum according to modern civil engineering education. So far, one journal paper and two conference papers have been submitted in the subject (Ouda et al., 2014 b; Omar et al., 2014; Ouda et al., 2016 b).

One of the research activities is observing existing engineering students about their motivation to be engineer. Faculties from within and outside the department who taught introductory engineering courses within PMU have worked in this study. As is used in the majority of engineering education research, the main method in this study is data collection through survey and interview to PMU engineering students and analysis of their course performances started at the freshmen level. So far the research results have indicated that there is high awareness amongst students about importance of engineers' role in the society such that it becomes the main driving factor for them to join engineering school. Their math and science skills are also investigated to show whether there is a strong correlation between awareness (i.e. motivation) and performance in the basic engineering courses. It is found so far that the students are in need to have strong contingency in math and science after their high school study to be connected with the essence of math and science use in engineering. It is anticipated that the research outcomes in this study will be used by instructor to improve teaching performance. Current study is ongoing investigating student motivation and its correlation to performance ranging from freshmen to senior.

Another type of research in this area is about curriculum upgrade based on student learning outcome achievements. Research method again is based on extensive data collection via a survey distributed to department's constituents including students, faculty, alumni and stake holder or employer. The research is actually part of routine exercise for departmental self-evaluation; however, scientific approaches with respect to learning outcomes are analyzed and contrasted with the data collected. The results have shown that basic cognitive learning outcomes in engineering need to be thoroughly examined and evaluated. An ongoing study is analyzing student performance extracted directly from teaching assessments contrasted with the previous study results that are obtained from the indirect (survey) assessment method.

\section{Discussion}

It can be observed from the above description that current active research areas at PMU Civil Engineering Department include: (1) environmental engineering with research themes on policy and management of water resources and solid waste management, (2) geotechnical engineering specializing in difficult soil and soil zonation applicable to the KSA region, (3) construction engineering and management with research themes on infrastructure asset management, (4) 

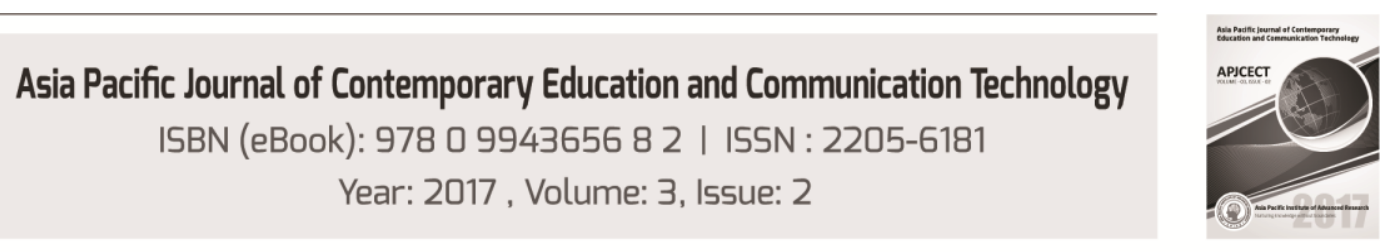

structural engineering focusing on structural performance of tall building utilizing innovative materials, and (5) engineering education with the focus on learning outcomes improvement. In total since 2011, the faculties have published more than 80 research papers in journals and conferences in which more than 60 percent of them published as refereed journal papers. This has indicated that publishing in a journal is preferred by the civil engineering faculty. This seems not a common practice at large research institutions where majority of the conference participation is funded through research grants held by respected researchers. However, the policy about conference participation at PMU has been very supportive since the faculty is entitled to get funded for three conferences per year, two international and one-regional. At the moment, a major challenge faced by the faculty is the backlog of applicants that need to be processed causing delay and difficulty keeping in pace with timelines set by conference organizer. This is one of the factors the faculty in civil engineering prefers publishing in journal despite big efforts are needed in preparing journal manuscripts relative to conference papers.

Since 2011 more than 50 percent of the papers published by the civil engineering faculty have been in the area of environmental engineering. Due to the nature of the research field focusing on applied environmental engineering, policy and management; data collection, synthesis, and analysis contrasted with extensive literature survey is one of the key strategies to execute the research work. The research issues can be readily assessed from statistical projection and analysis, and thereby anticipated research outcomes can be scientifically and arguably presented. This is different from the research that focuses on experimental and simulation requiring extensive resources such as laboratory facilities and computer tools in addition to availability of research assistants housed under graduate study. Investment in time and money in term of research facilities and graduate studies would need to be done to perform this type of research. Learning from this experience, the department has aligned its research strategies to conduct more applied research in the short and medium horizon without neglecting basic fundamental research in the civil engineering areas. For example, as mentioned briefly in the area of geotechnical engineering, current research activities have been focused on creation of zonation of soil characteristics using extensive data collection in form of survey and analysis. The expected research outcomes would be tremendous in term of saving money and energy in acquiring technical data for geotechnical engineering design work. Also, in the area of construction engineering and management, research in infrastructure asset management will use data collection and analysis based on survey distributed to city managers in various municipalities. It is also obvious that the expected impact by issuing infrastructure asset management can be direct and beneficial for policy makers in respected government.

The applied research in engineering is normally multidisciplinary in nature since it involves people ranging from statisticians, engineers, businessmen, social scientists, and policy makers. It is the type of research that can nourish in a young and growing research institution such as PMU. The impact of this type of applied research is anticipated to be immediate rather than facilitated through long term investment. As shown in the research activities, collaborations with external research partners can be implemented straightforwardly if the nature of research is multidisciplinary. Without collaboration it would be challenging for a young university to gain access to well-established research data, tools and instruments.

With respect to the governing research body at PMU which is carried by the Deanship of Research Development, the main supports are given in form of competitive research grants with the main intensions to spark new research ideas, to expand existing research interests, and to 


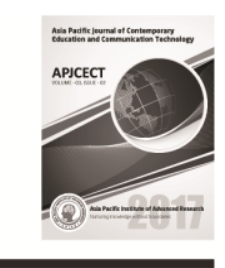

initiate external collaboration. Research proposals are solicited and winning proposals are given funding to execute their research plan within a short time period, e.g. one year. This is analogous to research seed fund administered by large research institutions with the main purpose giving research opportunities for young scholars to grow. At the moment, PMU as a private university is not eligible to apply for government based funding (e.g. KACST - King Abdullah City of Science and Technology) which regularly allocate research funds to various public institutions in KSA. Although individual faculty can apply as co-investigator under collaborative agreement with public university in KSA, this is still one of the biggest challenges faced by faculty particularly those who have long-term research investment and have concerns about intellectual rights. The immediate solution to tackle this issue is to establish strong research partnership between university and industry. PMU under the Deanship of Research Development is currently writing and updating policy and rules about research partnership including project consultation with industry. Again, by focusing on industry based funding to conduct research activities is not only supporting the researcher financially, but it is also in accordance with the university mission about applied research.

\section{Conclusions and Recommendations}

Limited resources at the onset of research infrastructure building are not considered to be major barrier in conducting research at the Department of Civil Engineering at PMU. Faculty in the department has been devoting time and energy creatively to run research activities. Multidisciplinary applied research in engineering is one research area that needs to be intensively developed and it has been demonstrated to be efficient so far for the department. However, research in engineering exploring basic strategies of experimental and or analytical hypothesis still needs to be conducted with different pace than those of applied research to maintain status of university as initiator of idea and innovation. This is to be in-line with the university mission in promoting more on applied research without neglecting basic research.

Research partnership between PMU and industry needs to be institutionalized since at the moment government based funding is not allocated to private universities such as PMU. Research that is supported by industry would have less bureaucracy and the expected research outcomes would be having direct and immediate impacts. It is anticipated that comprehensive policy and guidelines for industrial collaboration will be in place within next academic year.

Transportation engineering, which is one of the important fields in modern civil engineering, has not been activated in the department due to unavailability of faculty having the expertise in the area. It is anticipated that within next academic cycle civil engineering will have a new faculty with that expertise complementing existing civil engineering research fields. Master degree program in civil engineering is being developed and this would be anticipated to improve research performance at the department. 


\section{Asia Pacific Journal of Contemporary Education and Communication Technology \\ ISBN (eBook): 9780994365682 | ISSN : 2205-6181 \\ Year: 2017, Volume: 3, Issue: 2}

\section{References}

i. AlHarbi, M., Fnais, M., Al-Amri, A. \& Albdrahman, K., 2015. Site response assessment of AlKhobar, eastern Saudi Arabia, from microtremor and borehole data. Arab Journal of Geoscience.

ii. ASCE, 2013. Report Card for America's Infrastructure, New York: American Society of Civil Engineering.

iii. Asiz, A. \& Ahmed, D., 2013. Structural modeling and design of tall buildings composed of ultralightweight floor systems, 2013 World Congress in Structural Engineering and Mechanics, Sept 8-12. South Korea, s.n.

iv. $\quad$ Ayadat, T., 2016. Case Study: Design of Foundations in Liquefiable Site. International Journal of Engineering Research and Application.

v. Ayadat, T., 2016. Pathologie d'un bâtiment industriel à saint Césaire (Québec). Revue AlgérieEquipement, Volume 56, pp. 17-26.

vi. $\quad$ Ayadat, T., 2017. Correlation entre la résistance de cisaillement non drainé de l'argile de la mer de Champlain déterminée par le scissometre de chantier et le cone suédois. Paris, International Conference on Soil Mechanics and Geotechnical Eng.

vii. Ayadat, T., 2017. Méthode de réfection d'un glissement de terrain d'un tronçon de route. Algerian Journal of Scientific and Technology Research (AJSTR).

viii. Ayadat, T., Asiz, A. \& Ouda, O., 2016. Zonation maps for potentially collapsible and liquefiable soils in the south area of al-Khobar. Research project Phase II, s.l.: PMU University.

ix. $\quad$ Etezad, M., Hann, A. \& Ayadat, T., 2015. Bearing Capacity of Group of Stone Columns in Soft Soil. International Journal of Geomechanics (ASCE), 15(2).

x. Hanna, A., Ayadat, T., Etezad, M. \& Cros, C., 2016. Settlement of a Group of Stone Columns in Soft Soil. Revue Science des Matériaux, Laboratoire LARHYSS, Volume 7, pp. 7-16.

xi. Hanna, A., Foriero, A. \& Ayadat, T., 2015. Pullout Capacity of Inclined Shallow Single Plate Anchors in Sand. Indian Geotechnical Journal, 45(1), pp. 110-120.

xii. IPWEA and NAMS, 2012. Condition Assessment and Asset Performance Guidelines- Preamble Document", Institute of Public Works Engineering Australia and New Zealand Asset Management Support, s.l.: IPWEA and NAMS.

xiii. IPWEA and NAMS, 2015. International Infrastructure Management Manual -IIMM”, Institute of Public Works Engineering Australia and New Zealand Asset Management Support. 5th ed. Sydney: IPWEA and NAMS.

xiv. $\quad$ M.Ajmal, D.Ahmed \& A.Asiz., 2016. Structural Performances of Hybrid Tall Buildings Designed Using Ultra-Lightweight Floor Slabs, SEMC 2016: The Sixth International Conference On Structural Engineering, Mechanics and Computation. Capetown, s.n.

xv. Nizami, A. et al., 2016. The potential of Saudi Arabian natural zeolites in energy recovery. Energy, Volume 108, pp. 162-171.

xvi. Nizami, A. et al., 2015. Waste biorefinery in Makkah: a solution to convert waste produced during Hajj and Umrah Seasons into wealth. 15th Scientific Symposium for Hajj, Umrah and Madinah. [Online] Available at: doi:10.13140/RG.2.1.4303.6560.

xvii. Nizami, A. et al., 2015. An argument for developing waste-to-energy technologies in Saudi Arabia. Chemical Engineering Transactions, Volume 45, pp. 337-342. 
xviii. $\quad$ Nizami, A. et al., 2016. Developing Waste Biorefinery in Makkah: A Way Forward to Convert Urban Waste into Renewable Energy. Applied Energy. [Online] Available at: http://dx.doi.org/10.1016/j.apenergy.2016.04.11 [Accessed 11 April 2016].

xix. $\quad$ Ouda, K., 2013. Assessment of the Environmental Values of Waste-to-Energy in the Gaza Strip. Current World Environment, 8(3), pp. 355-364.

xx. Ouda, K., 2013. Review of Saudi Arabia Municipal Water Tariff. World Environment, 3(2), pp. 66-70.

xxi. Ouda, K., 2013. Towards assessment of Saudi Arabia public awareness of water shortage problem. Resources and Environment, 3(1), pp. 10-13.

xxii. Ouda, K., 2014. Impacts of agricultural policy on irrigation water demand: case study Saudi Arabia. International Journal of Water Resources Development, 30(2), pp. 282-292.

xxiii. Ouda, K., 2014. Water demand versus supply in Saudi Arabia: current and future challenges. International Journal of Water Resources Development, 30(2), pp. 335-344.

xxiv. Ouda, K., 2015. Domestic Water Demand in Saudi Arabia: Assessment of Desalinated Water as Strategic Supply Source. Desalination and Water Treatment, Volume 56, pp. 2824-2834.

xxv. Ouda, K., 2016. Treated wastewater use in Saudi Arabia: challenges and initiatives. International Journal of Water Resources Development, 32(5), pp. 799-809.

xxvi. Ouda, K., Al-Waked, R. \& Al-Shehri, A., 2014. Privatization of water supply services in Saudi Arabia: a unique experience. Utilities Policy, Volume 31, pp. 107-113.

xxvii. Ouda, K. \& Cekirge, H., 2014. Potential Environmental Values of Waste-to-Energy Facilities in Saudi Arabia. The Arabian Journal fo Science and Engineerinhg, 39(2), pp. 7525-7533.

xxviii. Ouda, K., Cekirge, H. \& Syed, R., 2013. n assessment of the potential contribution from waste-toenergy facilities to electricity demand in Saudi Arabia. Energy Conversuion and Management, pp. 402-406.

xxix. $\quad$ Ouda, K. et al., 2016. Waste to energy potential: A case study of Saudi Arabia. Renewable and Sustainable Energy Reviews, Volume 61, pp. 328-340.

xxx. $\quad$ Ouda, K. et al., 2013. Review of domestic. Applied Water Science water conservation practices in Saudi Arabia, Volume 3, pp. 689-699.

xxxi. $\quad$ Ouda, O., Asiz, A., Ayadat, T. \& Nayfeh, J., 2014. Performance measures of student learning outcomes for civil engineering at PMU, the 2nd Dubai International Conference in Higher Education: Sustaining Success through Innovation, 19-20 January 2014, the Conference Center. Dubai, UAE, s.n.

xxxii. Ouda, O., Ayadat, T., Asiz, A. \& Alghazo, Y., 2016. Utilizing Learning Outcomes Assessment for Civil Engineering Program Evaluation and Improvement - a Case Study. Journal of Scientific $\begin{array}{lll}\text { and Engineering Research. } & \text { [Online] }\end{array}$ Available at: http://jsaer.com/download/vol-3-iss-3-2016/JSAER2016-03-03-549-561.pdf

xxxiii. $\quad$ Ouda, O. K. M., Jawad, F., AL-Asad \& Asiz, A., 2014. An assessment of student's motivations to join College of Engineering: Case study at Prince Mohammad Bin Fahd University -

SaudiArabia. 2014 IEEE 6th Conference on Engineering Education (ICEED), Malaysia, Pages: 61 -66. [Online]

Available at: DOI: 10.1109/ICEED.2014.7194689 
xxxiv. $\quad$ PMI, 2011. Project Management Body of Knowledge -PMBOK Guide. 5th ed. s.l.:PMI.

xxxv. Rehan, M. et al., 2016. Pyrolytic liquid fuel: a source of renewable energy in Makkah. Energy. Recovery, Utilization, and Environmental Effects, 38(17), pp. 2598-2603.

xxxvi. Sadef, Y. et al., 2016. Waste-to-energy and recycling value for developing integrated solid waste management plan in Lahore. Energy Sources, Part B: Economics, Planning, and Policy, 11(7), pp. 569-579. 